\title{
Aerodynamic interference of wind flow around three cylindrical bodies with surface roughness
}

\author{
Michael Macháček ${ }^{1, *}$, Shota Urushadze $^{1}$, Stanislav Pospíšil ${ }^{1}$, Arsenii Trush $^{1}$ \\ and Miroš Pirner ${ }^{1}$ \\ ${ }^{1}$ Czech Acad Sci, Inst Theoret \& Appl Mech, Prosecká 76, 19000 Prague, Czech Republic
}

\begin{abstract}
The aerodynamic interference effect is an important and complex phenomenon that can modified wind flow around structures in a group and wind loading on structures can significantly increase. Three cylindrical buildings in one row with a rough surface and surrounding lower minor buildings were studied by experimental measurement in wind tunnel with a turbulent boundary layer. The experimental study was focused on aerodynamical forces, local dynamic pressure on a facade of the buildings, and visualization of wind flow around buildings.
\end{abstract}

\section{Introduction}

In many cases of high-rise building design it is necessary to make verifying experimental measurement on a small aerodynamic model in a wind tunnel to determine wind loading. It holds especially for the cases, when the buildings have high roughness façade and are in the group. In the presented case, three building with almost cylindrical shape of close to each other were examined. Wind loading on close structures interfere and an impact of the wind on the group of buildings can rise compared to the case with a single structure.

Interference effect is well-known phenomena, but it is also very complex issue with many options. Usually general simplified approach cannot be used. Many studies related to the interference effect among highrise buildings have produced useful results. Authors of [1] studied interference excitation on two square and cylindrical prisms in low turbulent wind environment and defined increasing of the response of the downstream building, this effect was called "resonant buffeting". Aerodynamic forces acting on two static square prisms placed vertically in a turbulent boundary layer are described in [2] where an ideal distance between prisms was found, and there was observed a significant increase of mean and fluctuation component of aerodynamical forces. Three building were presented in [3] where the change of the changing the mean aerodynamic coefficient was analysed. The spectral density of interfered wind loading on three square prisms is well described in [4]. Authors of [5] focused on local pressure on facades of two square prisms at different high level, where a noticeable increase of the local pressure, especially in the lower frequency spectrum of wind loading, was observed. Paper [6] extends the previous study for a different high of a square prisms, there examined four different twins of square prisms where was analysed local pressure, each twin has the same high. Experimental work [7] is

* Corresponding author: machacek@itam.cas.cz 
focused on the interference effect of two rectangular buildings, with many positions included also non-perpendicular positions. Transverse vibration behaviour of cylinders in line was examined in [8], authors focused on the aerodynamic response of two, three and four circle cylinders in one line. There, the authors defined critical spacing between smooth surface cylinder and a critical angle of wind attack with respect to the row of cylinders prone to oscillating.

Presented work is focused on the examination of the aerodynamic coefficients and local pressure of three buildings with almost cylindrical shape, with different height and considerable roughness of the façade. Buildings are placed in the complex terrain of the town Tbilisi in Georgia. The study was made to define aerodynamic forces for the proper design of the building also with the aim to increase the knowledge about the interference effect between more buildings with high roughness.
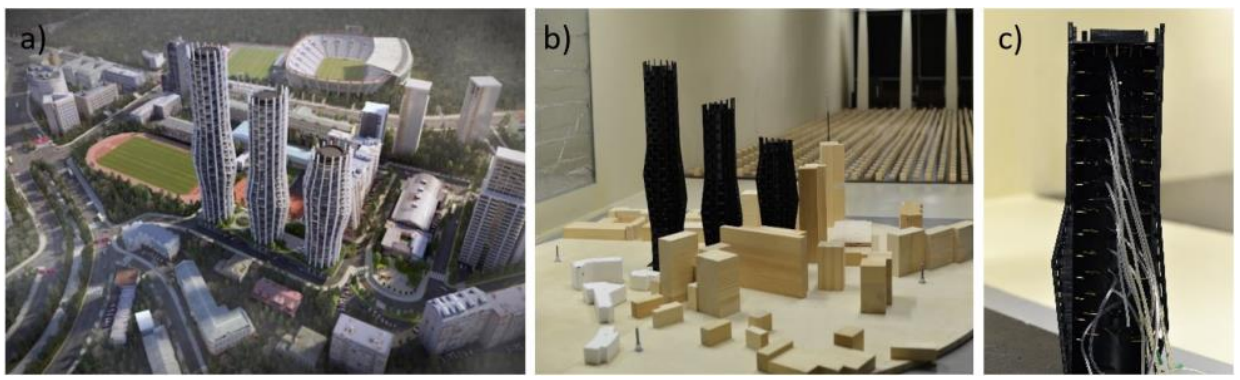

Fig. 1. Visualisation of the buildings (a) and experimental model placed in a wind tunnel (b) pressure tubes (c).

\section{Experimental model}

In the real situation, the building site has three solitary buildings with the heights $H_{1}=150$ $\mathrm{m}, H_{2}=120 \mathrm{~m}, H_{3}=95 \mathrm{~m}$, and they are placed in one row on one base height $h=10 \mathrm{~m}$, so highs from the ground each tower are $H_{e l, 1}=160 \mathrm{~m}, H_{e l, 2}=130 \mathrm{~m}, H_{e l, 3}=105 \mathrm{~m}$. Distance between the buildings is the same, i.e., $L=47 \mathrm{~m}$. As it is shown on Fig. 1(a,b,c) crosssection is not same of diameter on entire hight of building and the average diameter of the cross-section is the same for all buildings $D=50 \mathrm{~m}$. In this study the buildings are labelled sequentially; the highest one is labelled 1, the middle one is 2 and the lowest building is 3 .

The buildings are placed in an urban area with many urban surroundings which were modelled in radius approximately $250 \mathrm{~m}$ of the full-scale as shows Fig. 1b. Sketch of the surrounded building with the marked direction of the wind is shown on Fig. 2a. The models of all 3 buildings were printed on the $3 \mathrm{D}$ printer according to the drawings of real construction sketches. The printed model was designed with the possibility to be opened, thus for example to allow to access the pressure sensors. Both two parts of each building were connected together by the steel bolts. For the base of the buildings was used a wood slab on which models were screwed. Special attention has been paid to the shape of part of the facades, which has been modelled into detail, see Fig 3 . The surface of buildings thus reflects the balconies reflecting the real buildings and the roughness of the facade is thus much higher than the usual modern glass façades common for the high-rise building. 


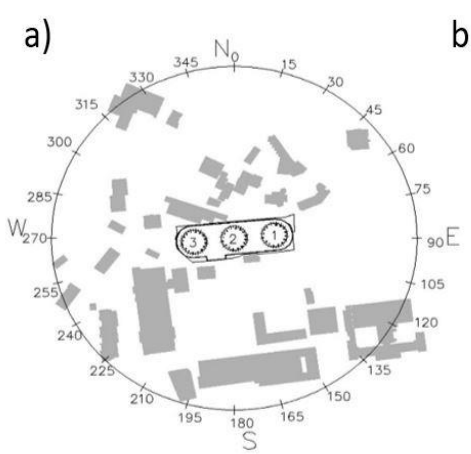

b)

Fig. 2. The orientation of the model at between buildings a) placed and labels of pressure taps b).

Laboratory experiments were carried out in the Climatic Wind Tunnel (CWT) of the Institute of Theoretical and Applied Mechanics, Czech Academy of Sciences. CWT is designed as a closed-loop boundary layer wind tunnel with controlled flow velocity and temperature. It consists of the climatic and aerodynamic sections. The aerodynamic section provides appropriate conditions to study wind effects on downscaled models of prototype objects. The incoming flow was turbulent flow with the boundary layer. The modelled atmospheric boundary layer was fitted to an urban topography IV, with surface roughness length $z_{0}=1 \mathrm{~m}$. terrain category acording to ČSN EN 1991-1-4 [9], scaled-down at the simulation length scale factor 1:250. A detailed description of the used turbulent boundary layer is in [10]. The flow speed and reference pressure were measured $2 \mathrm{~m}$ in the front of buildings upstream direction, by Prandtlt-Pitot tube, at a height of $45 \mathrm{~cm}$ from the wind tunnel floor, see Fig. $1 \mathrm{~b}$.

\section{Local pressure measurement}

The pressure taps were made as small $1 \mathrm{~mm}$ holes on the examined surface to fit the $20 \mathrm{~mm}$ long brass tubes that were adapters for the silicone tubes. The pressure taps were displaced equidistantly along the surfaces of the model. The average distance between the taps in the vertical directions was $38 \mathrm{~mm}$ and in the horizontal direction $24 \mathrm{~mm}$. At the facades, the pressure taps were also mounted in the proximity of the balconies. The taps were perfectly normal to the surface and were free of burrs. Brass pressure taps were connected with pressure scanner Scanivalve DSA 3217 by silicon tubes systems, length of $1000 \mathrm{~mm}$, see Fig 1c. In total, 683 pressure taps were placed on the model. Most of the pressure taps were positioned to measure the outer surface pressures on the model (656) and the 27 for measuring the pressures on the top of the buildings. Each tower had 16 pressure taps in one level and the highest Tower 1 has 17 measured levels, Tower 2 had 14 measured levels and the smallest Tower 3 had 10 measured levels. Each pressure taps is labelled as shown figure $2 \mathrm{~b}$, line of building row is slightly rotated by $5^{\circ}$ from the principal wind direction. The experimental model of all buildings was rotated by 15 degrees, so that whole wind rosette (all principal wind directions) was covered. There were 25 measurements per experiment with the double measurement at $360^{\circ}$ or $0^{\circ}$, respectively, in order to investigate the results of successive recurrences. Influence of freestream velocity on local pressure coefficients was tested for range $3 \mathrm{~m} / \mathrm{s}$ to $18 \mathrm{~m} / \mathrm{s}$ for one wind direction. In range $6 \mathrm{~m} / \mathrm{s}$ to $18 \mathrm{~m} / \mathrm{s}$ was measured almost the same coefficients with negligible deviation. The freestream velocity for all local pressure measurement was $16 \mathrm{~m} / \mathrm{s}$ due to utilize of the entire range of sensor resolution. The length of one measurement record was $30 \mathrm{~s}$. 

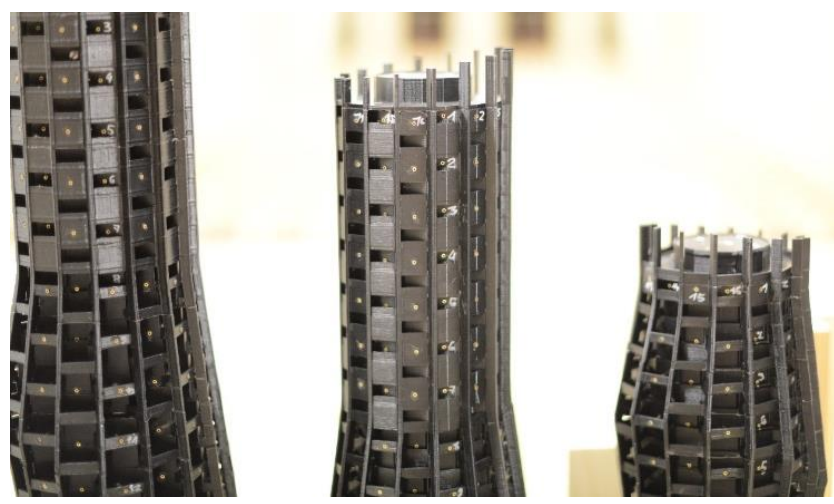

Fig. 3. View on the facade of towers with balcony.

Coefficient of local pressure $C p$ was defined as the ratio equal to local dynamic pressure on facade divided by dynamic pressure from Prandtlt-Pitot tube. First, an important issue was to define maximal and minimal local pressure coefficient on façade. Surface plots on Fig. 2 shows the minimal (a) and maximal (b) local mean pressure coefficients of measurement for all directions of the wind flow, so it represents the envelope of the pressure loading on the façade from all of the available direction of the wind. On the x-axis is the location of the spot as labelled on Fig. 2b. and on axis $y$ is the height of the towers measured from the ground. Fig $4 \mathrm{~b}$, show that on the spot near to gap between the towers, there are only negative values of $C p$, it means wind loading act only as suction.
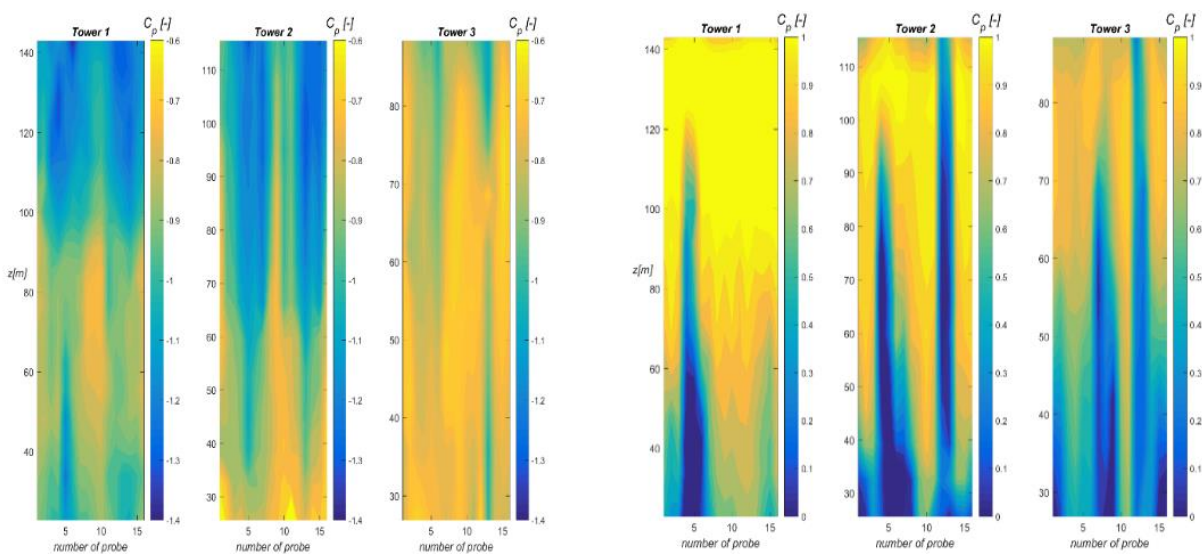

Fig. 4. Surface plot of minimal coefficients of local pressure $C p$ (a) and maximal of local pressure (b). 

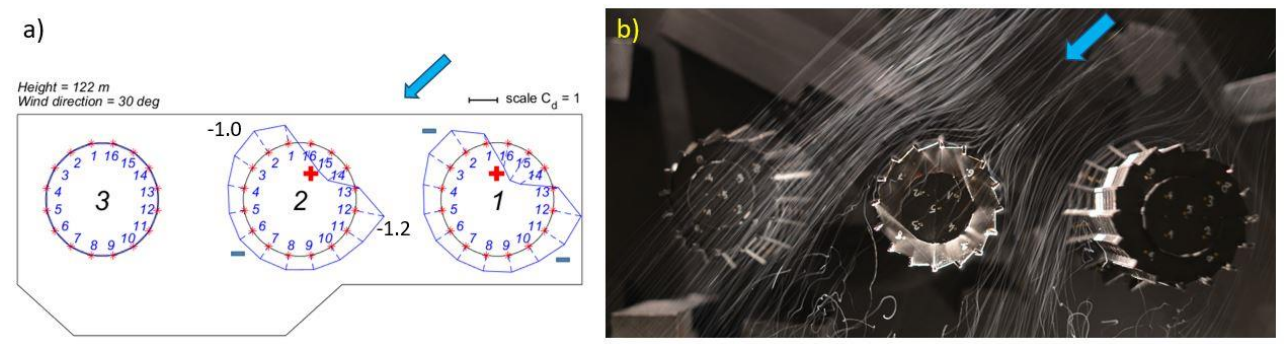

Fig. 5. Graphical representation of local pressure $\mathrm{Cp}$ (a) and visualization of airflow around towers (b) in height $122 \mathrm{~m}$.

For a better understanding of wind flowing around the towers, the visualisation of airflow by helium bubbles has been carried out. Fig. 5a shows the results of the mean local pressure coefficient in direction of wind $30^{\circ} \mathrm{NE}$ on the towers in the $122 \mathrm{~m}$ elevation above the ground. The elevation of plotted pressure taps is above the top of the lowest Tower 3 . An increase of the suction by $20 \%$ was observed on the side near the gap. This is obviously caused by the acceleration of wind speed between towers as show Fig. $5 \mathrm{~b}$.
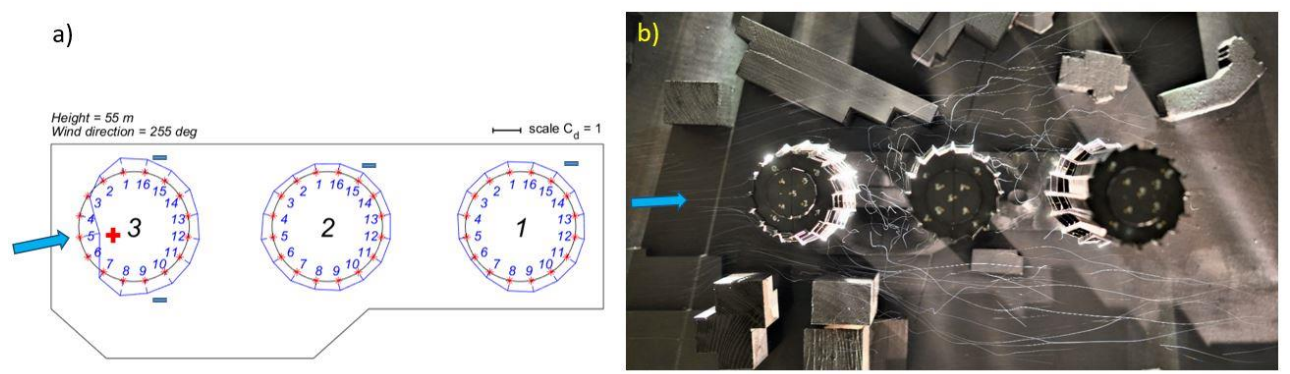

Fig. 6. Graphical representation of local pressure $C p$ (a) and visualization of airflow around towers (b) in height $55 \mathrm{~m}$.

Fig. 6a shows the results of the mean local pressure coefficient in direction of the wind, being $255^{\circ} \mathrm{SW}$ and in the height $55 \mathrm{~m}$ above the ground. This case is typical for the phenomenon called "shielding". The Tower 3 placed upstream act as the shield for other building in the near area of downstream. In plotted elevation, wind causes only suction on façade of Tower 1 and 2.

\section{Aerodynamic coefficients}

Next important issue was to determine the aerodynamic coefficients of the towers to obtain aerodynamic forces and bending moment at the foundation. The models were fixed to a sixaxis force balance sensor. Two types of ATI Industrial Automation sensors Nano 25 and Mini 40 with six-axis load cell was used for measurement wind-induced reaction forces at the bottom of the model. Tower 1 (highest) was measured by the sensor Nano 25 and Tower 2 and 3 were measured by the sensors Mini 40.

The group of all buildings was rotated by step 5 degrees so that the complete wind rosette (all principal wind directions) was covered. There were in total 73 measurements per experiment with the double measurement at $360^{\circ}$ or $0^{\circ}$. Influence of freestream velocity on aerodynamic coefficients was tested for range $3 \mathrm{~m} / \mathrm{s}$ to $14 \mathrm{~m} / \mathrm{s}$ for one wind direction. In range $6 \mathrm{~m} / \mathrm{s}$ to $14 \mathrm{~m} / \mathrm{s}$ was measured almost the same coefficients with negligible deviation. The freestream velocity for all measurement of aerodynamic coefficients was $10.5 \mathrm{~m} / \mathrm{s}$ with 
respect on toughness and resistance of the experimental model. The length of one measurement record was $30 \mathrm{~s}$.

The Aerodynamic drag coefficient $C d$ is given by Eq. (1), where $F d$ is mean aerodynamic force in the wind direction, $U$ is the reference free field wind velocity, $\rho_{\text {air }}$ is density of air and $A_{x}$ is the projected area of the tower (perpendicular to the wind flow). In the presented case, the area of the towers was considered as $A_{1}=601 \mathrm{~cm}^{3}$ (highest tower), $A_{2}=472 \mathrm{~cm}^{2}$ (middle tower), and $A_{3}=364 \mathrm{~cm}^{2}$ (lowest tower). Aerodynamic lift coefficient $\mathrm{Cl}$ is given in Eq. (2), where $\mathrm{Fl}$ is the mean lift force which is perpendicular to the wind flow direction.

$$
\begin{aligned}
& C d=2 \cdot F d /\left(\rho_{\text {air }} \cdot A_{x} \cdot U^{2}\right) \\
& C l=2 \cdot F l /\left(\rho_{\text {air }} \cdot A_{x} \cdot U^{2}\right)
\end{aligned}
$$

Fig. 7b shows the aerodynamic drag coefficient $C d$. This coefficient expresses normalized nondimensionalized aerodynamic force in the wind direction. The mean wind loading on Tower 1 is the highest, as the few highest level are not in the "shielding" zone behind other structures. Wind loading on Tower 1 has two characteristic local minima. The first one is registered at $55^{\circ}(\mathrm{NE})$, where Tower 1 is shielded by a relatively high surrounding building. The second on is at $265^{\circ}$ (SW) direction, where it is shielded by the Towers 2 and 3, while the value of the coefficient decrease to $C d=0.65$. The worst direction for Tower 1 is $125^{\circ}(\mathrm{SE})$ where the coefficient has its maximum, $C d=1.45$. Wind loading on Tower 2 has in general lower drag coefficient then Tower 1. It also has two characteristic local minima. The first local minimum of $C d$ decreased to almost zero in $80^{\circ}(\mathrm{NE})$, where the building is completely shielded by the Tower 1 . The second local minimum $C d=0.42$ for $255^{\circ}(\mathrm{SW})$, where is partly shielded by Tower 3. Two maxima values for Tower 2 are almost the same $C d=1.27$ for $160^{\circ}(\mathrm{SE})$ and $0^{\circ}(\mathrm{N})$ direction of the wind. The drag coefficient of Tower 3 is the lowest, due to shielding by surrounding buildings and in lower height is lower wind speed due to the boundary layer.

a)

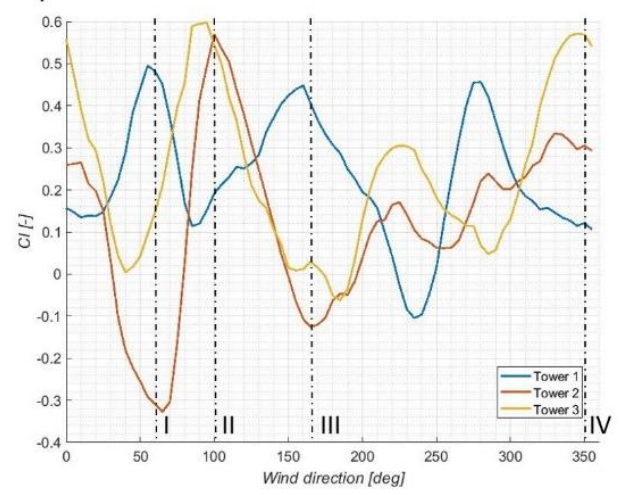

b)

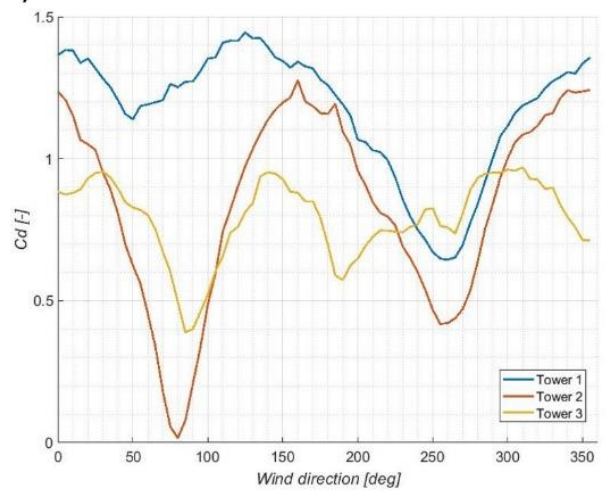

Fig. 7. Aerodynamic coefficient of lift $C l$ (a) and aerodynamic coefficient of drag $C d$ (b).

Fig. 7a shows the aerodynamic coefficient of the lift $\mathrm{Cl}$. This coefficient expresses a normalized aerodynamic force in the perpendicular direction to wind direction. The convention of the sign is depicted on Fig. 8. This force is caused only by phenomena of interference of wind between towers and surrounding building and by asymmetricity of Tower, but asymmetricity has a minor contribution to lifting forces in the presented case. A symmetrical cylinder in wind flow with boundary layer has lift force equal to zero. 


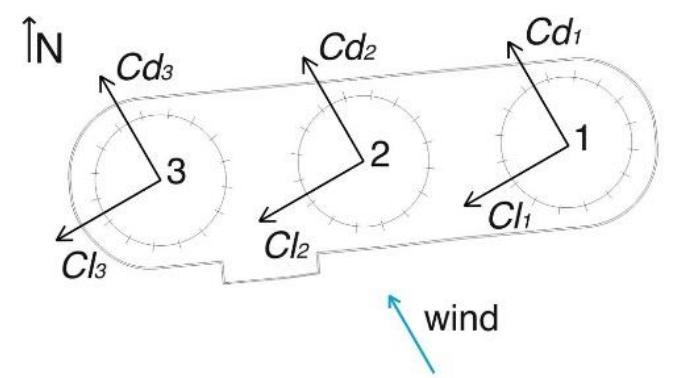

Fig. 8. Sign force convention - Cartesian coordinates.

Four local extremes as marked I-IV on Fig 7a) are plotted as the sketch of aerodynamic forces acting on towers in real directions. Fig. 9 show real direction of forces in two directions of wind $65^{\circ}(\mathrm{NE})$ marked as I and $100^{\circ}(\mathrm{SE})$ marked as II, where was the largest value of $C l=0.59$ for Tower 3 and $C l=0.56$ for Tower 2 .
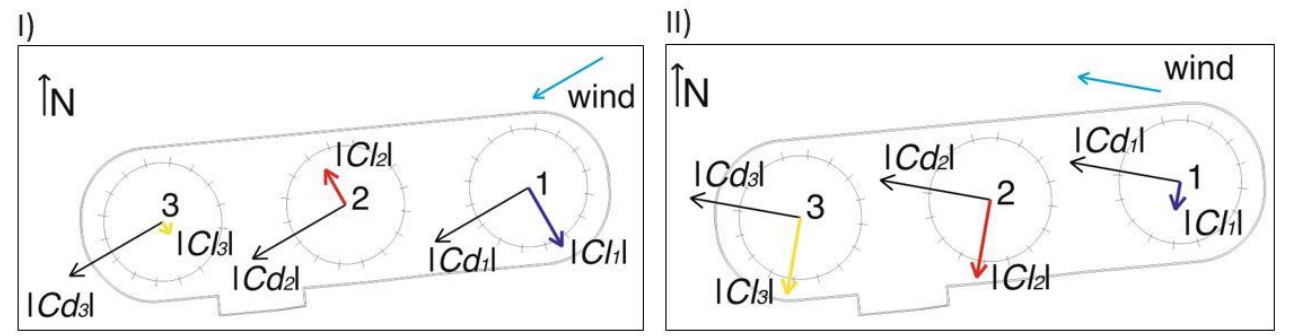

Fig. 9. Plotted direction of wind force, wind direction I and II.

Fig. 10 show real direction of forces in two directions of wind $165^{\circ}(\mathrm{SE})$ marked as III and $355^{\circ}(\mathrm{NW})$ marked as IV. As shown in Fig. 7a, 9 and 10, the aerodynamical coefficients of lift forces are variable in small change of wind direction. This can cause instability problem as galloping.
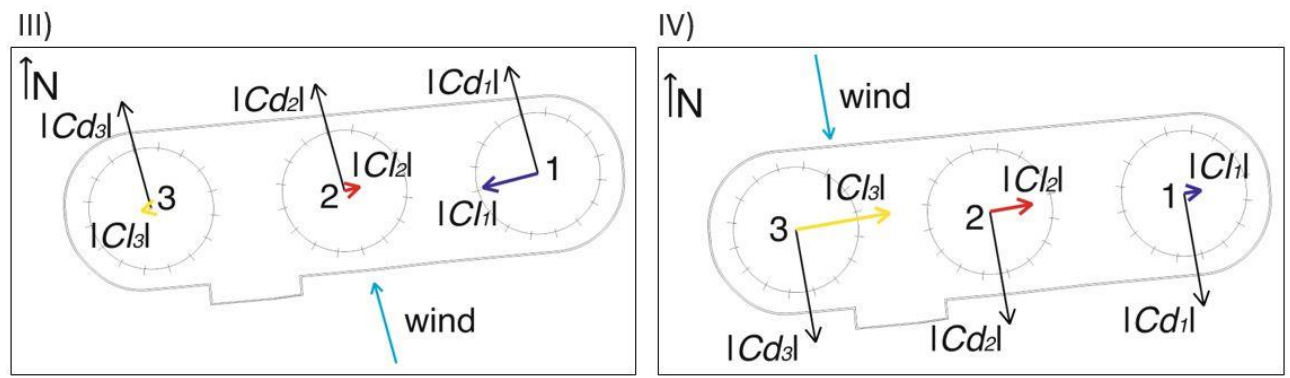

Fig. 10. Plotted direction of wind force, wind direction II and IV. 


\section{Conclusion}

Experimental analysis of mean wind loading on three high rise buildings showed noticeable interference-effect. This phenomenon is observed especially in some wind direction where the substantial increase in the local pressures occurs. The closest surface to the gap between towers is typical for increasing of suction (negative value $\mathrm{Cp}$ ). On the other hand it is only suction in this zone, because other towers act as shield and pressure loading (positive value $C p$ ) disappear in the geometry of towers. Maximal value of the suction on the facade was measured to be $C p=-1.38$ while the maximum pressure was $C p=0.98$. The lift coefficient on towers can not be neglect. The experimental measurement showed that the coefficient of lift force can reach $\mathrm{Cl}=0.6$ and the drag coefficient $\mathrm{Cl}=1.45$. When the Tower 2 is in the downstream of the Tower 1, the aerodynamic forces decrease almost to null. Visualisation of airflow around the towers clarified the character of the wind flow near the towers and enabled to compare wind forces and the local pressure with the wind streamlines.

This research was financially supported by the project GAČR No. 19-04695S of the Czech Science Foundation.

\section{References}

1. P.A. Bailey, K.C.S. Kwok, Interference excitation of twin tall buildings, J. Wind. Enh. Ind. Aerod. 21, 323-338 (1985)

2. H. Sakamoto, H. Haniu, Aerodynamic forces acting on two square prisms placed vertically in a turbulent boundary layer, J. Wind. Enh. Ind. Aerod. 31, 41-66 (1988)

3. Z.N. Xie, M. Gu, Mean interference effects among tall buildings, J. Eng. Struct. 26, 1173-1183 (2004)

4. Z.N. Xie, M. Gu, Simplified formulas for evaluation of wind-induced interference effects among three tall buildings, J. Wind. Enh. Ind. Aerod. 95, 31-52 (2007)

5. Y. Xianfeng, Z. Xie, J.B. Zhu, M. Gu, Interference effects on wind pressure distribution between two high-rise buildings. J. Wind. Enh. Ind. Aerod. 142 (2015)

6. W. Kim, Y. Tamura, A. Yoshida, Interference effects on local peak pressures between two buildings, J. Wind. Enh. Ind. Aerod. 99, 584-600 (2011)

7. Y. Hui, A. Yoshida, Y. Tamura, Interference effects between two rectangular-section high-rise buildings on local peak pressure coefficients, J. Fluids Struct. 37, 584-600 (2013)

8. W. Hanenkamp, W. Hammer, Transverse vibration behaviour of cylinders in line, J. Wind. Enh. Ind. Aerod. 57, 343-351 (1995)

9. ČSN EN 1991-1-4, Eurokód 1: Zatížení konstrukcí - Část 1-4: Obecná zatížení - Zatížení větrem (2013)

10. S. Kuznetsov, M. Ribičić, S. Pospisil, M. Plut, A. Trush, H. Kozmar, Flow and Turbulence Control in a Boundary Layer Wind Tunnel Using Passive Hardware Devices, Exp. Tech. 41 (2017) 